Kansas State University Libraries

New Prairie Press

Conference on Applied Statistics in Agriculture

1997 - 9th Annual Conference Proceedings

\title{
ANALYSIS OF A MIDWEST FARMER SURVEY OF PEST INFESTATION
}

Susanne Aref

Follow this and additional works at: https://newprairiepress.org/agstatconference

Part of the Agriculture Commons, and the Applied Statistics Commons

\section{(c) $(1) \ominus$}

This work is licensed under a Creative Commons Attribution-Noncommercial-No Derivative Works 4.0 License.

\section{Recommended Citation}

Aref, Susanne (1997). "ANALYSIS OF A MIDWEST FARMER SURVEY OF PEST INFESTATION," Conference on Applied Statistics in Agriculture. https://doi.org/10.4148/2475-7772.1298

This is brought to you for free and open access by the Conferences at New Prairie Press. It has been accepted for inclusion in Conference on Applied Statistics in Agriculture by an authorized administrator of New Prairie Press. For more information, please contact cads@k-state.edu. 


\title{
ANALYSIS OF A MIDWEST FARMER SURVEY OF PEST INFESTATION
}

\author{
Susanne Aref \\ University of Illinois at Urbana-Champaign
}

\begin{abstract}
A survey of farmers rating the severity of crop pest infestation in their fields was conducted in the Midwest in 1992. The purpose of the present study was to determine summary variables of the pest infestation ratings and the effect of region, soil type, and tillage on these summary variables. The pests were in the following six categories: perennial and annual weeds, insects and diseases of corn (Zea mays L.) and insects and diseases of soybean (Glycine max (L.) Merrill). Categorical models were used to analyze individual pest ratings. A non-parametric method, the Sheirer-Ray-Hare extension of the Kruskal-Wallis test to factorials, was used as a substitute when categorical model analysis failed. When both methods could be performed the results were very similar and were also close to results of general linear model analysis of the raw data. Region and tillage were the most significant factors. Variables for which tillage was significant had higher mean ratings in no-till than in conventional till. When region was significant the eastern region had higher mean ratings than the western region in most cases. Principal component analyses produced several informative summary sets of three, seven, and thirteen eigenvalues, respectively. The three rotated components using three eigenvalues consisted of soybean pests, perennial and annual weeds, and corn pests, respectively. These rotated components showed a strong partitioning for region and tillage, and to a lesser degree for soil type. Using seven eigenvalues resulted in further division of components. The corn pest component of the three eigenvalues was divided into a component of corn insects and a component of corn diseases. The rotated components based on thirteen eigenvalues further divided the soybean pests into a component of insects and a component of diseases, and divided each of the perennial weeds, annual weeds, and corn insects into components of higher and lower mean ratings. Analyses of each of the sums of variables loading on the thirteen rotated components resulted in a very highly significant $(\mathrm{p}<0.0001)$ tillage effect in all but one sum. The region effect was very highly significant in half of these variable sums, while the soil type effect was very highly significant in only three sums.
\end{abstract}

KEYWORDS: non-parametric factorial analysis, principal components, component analysis

\section{INTRODUCTION}

Weeds, insects and plant diseases are serious problems for producers throughout the Midwest. Developers of new products and resistant varieties may benefit from knowledge of perceived infestation levels in farmers fields (Loux and Berry, 1991). A survey of farmers was conducted in the twelve corn belt states in the Midwest in 1992. The survey evaluated the perceived severity of infestation of crop pests in farmers fields. Other more limited surveys on weed distribution have been done for corn and soybeans in Illinois (Stoller et al., 1993) and Ohio and for wheat in North Dakota (Dexter et al., 1981) but no other comprehensive survey is publicly available. Principal component analysis may be used as a tool to summarize the large number of pest infestation ratings. 


\section{SURVEY COMPOSITION AND RESULTS}

The survey was mailed to more than 30,000 farmers and had a response rate of $7 \%$, or 2,440 responses. Of this number only 1598 contained complete information about tillage and soil type. The survey results are ratings of pest infestation as perceived by farmers in twelve combinations of region, tillage and soil type conditions. A pest, such as soybean cyst nematode, which is difficult to detect, may appear with lower ratings than expected when compared to more visible pests (see Fig. 1 for a list of pests and their mean ratings). The crops considered in the survey were corn, sorghum, soybean, and wheat. To assure a reasonable response rate the survey was kept as simple and short as possible. The questions used common names of pests. Spider mites were listed along with the insects. For simplicity insects and diseases of corn and sorghum were considered together (both corn and sorghum pests will be referred to as corn pests here).

The Midwest was divided into an eastern region and a western region reflecting both more precipitation in the eastern region than in the western region, and a difference in acreage composition of corn and sorghum in the two regions. The mailed-out survey differed in the two regions. Both survey versions included ratings of infestation of weeds, soybean pests and corn pests, most of these common to both regions. The western survey also included wheat pests. In all 64 pests were rated in two versions of the survey. The present paper only considers pests common to both regions, which were perennial and annual weeds, corn insects and diseases, and soybean insects and diseases. Two ratings of different generations of European corn borers were averaged to one corn borer rating; in all only 40 pest ratings were used here (Fig. 1).

The conventional till and no-till acreages do not fall into two distinct groups. The survey responses had a bimodal distribution of percentage no-till acreage with modes at $15-20 \%$ and 40 $50 \%$. A decision was made to consider a 30\% (and above) no-till acreage as predominantly no-till and the rest as predominantly conventional till. Soil type was determined by survey responses, which were (predominantly) clay, loam or sand. A project report by Pike et al. (1997) contains the geographic distribution and infestation severity maps of each pest.

Correlations between infestation ratings within each pest category were used to better understand the summary variables identified by rotated components in principal component analyses. The effects of region, soil type and tillage on individual infestation ratings and summary variables were determined through categorical model analysis or non-parametric analysis of factorial experiments. The number of survey responses from each region, soil type, and tillage combination is shown in Figure 2.

\section{CORRELATIONS OF PEST RATINGS}

Not all correlations of infestation ratings within each pest category were significant at the 0.0001 level. This is surprising, since even random clouds may exhibit a significant correlation for such a large number of observations. The correlation of 0.07 between two annual weeds, shattercane and lambsquarter, was significant at 0.01 but not at 0.001 . The correlation of 0.04 between two perennial weeds, quackgrass and hemp dogbane, was not significant at 0.05 indicating no relationship between the two weeds. It might be expected that a farmer who gives one pest a high rating would tend to do so with other pests as well. The two correlations that are not significant at 0.0001 refute that proposition or at least indicate that it is not generally true. All other correlations were significant at the 0.0001 level. Correlations in the weed categories otherwise ranged between 0.14 and 0.41 in perennial weeds and between 0.11 and 0.59 in annual weeds. In corn insects correlations ranged from 0.22 to 0.61 while correlations in soybean insects and in crop diseases ranged from 0.47 to 0.69 . Of the very highly significant $(0.0001)$ correlations only nineteen were significant across all region, soil type and tillage combinations (data not shown). These correlations were mainly in the soybean disease, annual weed and corn insect categories. 


\section{PRINCIPAL COMPONENT ANALYSIS}

Principal component analysis was carried out using SAS ${ }^{\mathrm{TM}}$ PROC FACTOR with options METHOD=PRIN and ROTATE=VARIMAX. Though the variables in this data set were not normally distributed, there were enough observations (1598) to ensure adequate analysis. A common procedure to determine the number of relevant components to retain was followed (Hatcher and Stepanski, 1994). Pest ratings are the variables in the analyses. Each of the rotated components themselves, the sums of the variables that load on the rotated components, and the means of each of the six pest categories are the summary variables considered.

For this data set the number of components to retain was not clearly determined, since three different criterias to reduce the number of eigenvalues to be considered resulted in three different numbers of variables to retain (three, seven, and thirteen). The first eigenvalue was five times as large as the second while the second eigenvalue was only ten times as large as the 40'th eigenvalue. The criteria of considering only eigenvalues greater than 1 resulted in seven components. This number was one of the choices supported by the scree plot (Fig. 3). The seven first eigenvalues together accounted for $55.5 \%$ of the variation, but the fourth through seventh eigenvalue only contributed from $3.9 \%$ to $2.7 \%$. The criteria of including eigenvalues to $70 \%$ of the variation resulted in 14 eigenvalues. One of the natural breaks in the scree plot was at 13 rather than 14. Since the first 13 eigenvalues accounted for $68.3 \%$ of the variation, 13 eigenvalues was chosen. Finally, the criteria of considering only eigenvalues contributing at least $5 \%$ resulted in just three eigenvalues. So in essence, summary variables determined by the rotated components were considered for the selection of three, seven and thirteen components, respectively (Table 1). The variable loading cut-off point was made at the 0.45 level rather than the usual 0.40 level, since this gave clearer classification of the variables.

\section{Three eigenvalues}

If only three eigenvalues were used the rotated components consisted of soybean pests, weeds, and corn pests (Table 1). All soybean pests loaded on the first component. Three of five perennial weeds and eight of fourteen annual weeds loaded on the second component. All corn insects and three of the four corn diseases loaded on the third component. In all 31 (of 40) pests were included in the rotated components. The variance explained by these three components was $5.8,5.7$, and 5.4, respectively.

\section{$\underline{\text { Seven eigenvalues }}$}

Keeping seven eigenvalues in the analysis created a first rotated component of two perennial weeds and eight annual weeds with an explained variance of 5.2 (Table 1). These weeds had the highest mean ratings of the weed categories except for the second highest annual weed (velvetleaf). Velvetleaf had loadings of 40 on both components 1 and 7 (this would exclude the weed also if 40 rather than 45 had been the cut-off point). The second component was all soybean insects and diseases with an explained variance of 4.3. Seedling blight was kept as loading on component 2 even though this disease also loaded on component 4 , because the load on component 2 was 56 and the load on component 4 was just 45 . Components 1 and 2 were constructs similar to the first two components of the three eigenvalues just discussed, except that the order of the components was switched. The third component was seven of the nine corn insects with an explained variance of 4.2. Grasshoppers were not included since they loaded both on components 3 and 5. Fourth, with an explained variance of 2.6, was the four corn diseases. Thus the first four components of the seven-eigenvalue case correspond to the three components of the threeeigenvalue case. The difference is that the corn pest component of the three-eigenvalue case was divided into a corn insect component and a corn disease component in the seven-eigenvalue case.

The remaining three components of the seven-eigenvalue case were as follows: a perennial weed (hedge bindweed), an annual weed (prickly lettuce), and a corn insect (chinchbug); two 
annual grass weeds (fall panicum and crabgrass); an annual grass weed (shattercane). The explained variances of these components were $2.4,1.9$, and 1.5, respectively. One perennial weed (quackgrass) loaded on both components 6 and 7 and another (hemp dogbane) had loadings of 40 (less than the 45 cut-off point) on components 1 and 7 . Here three of five perennial weeds, all annual weeds, all soybean pests, all corn diseases, and eight of nine corn insects were included in the rotated components, in all 37 of 40 pests possible.

Quackgrass and hemp dogbane were the pair of perennial weeds, which had ratings that were not correlated. Of the pair of annual weeds which had ratings that were only correlated at the 0.01 level, shattercane loaded on component 7 , while lambsquarter loaded with the majority of the annual weeds on component 1.

The set of seven eigenvalues divided the corn pests into two categories, corn insects and corn diseases, while weeds were divided into several subgroups. This analysis pointed towards using the same summary variables (weeds, corn pests, and soybean pests) as the three-eigenvalueanalysis indicated except for using each of the corn pest categories (insects and diseases) by themselves.

\section{Thirteen eigenvalues}

The variances explained by the first two rotated components retaining 13 eigenvalues were 3.8 and 3.6, respectively (Table 1). The first rotated component was five of the nine corn insects. These five insects (rootworm, corn borer, cutworm, stalk borer, and wireworm) together with grasshoppers had the six highest mean ratings of corn insects. Of the five insects only wireworm had a mean rating less than the mean rating of grasshoppers (Fig. 1). The second component was the seven annual weeds which together with cocklebur had the highest mean ratings; cocklebur with the third highest mean rating had a higher loading on component 9.

The variance explained by components 3,4 , and 5 was $2.7,2.6$ and 2.5 , respectively. The third component was three of the soybean diseases. Soybean cyst nematode loaded equally on components 3 and 4 and was excluded from both components. The fourth component was three of the soybean insects. The fifth component was all four corn diseases.

The variance explained by the remaining eight components was less than 2 each. The sixth component was two perennial weeds with high mean ratings, Canada thistle and quackgrass. Thistles had the highest mean rating while quackgrass and common milkweed had practically the same next highest mean ratings of 1.04 and 1.05 , respectively. The seventh component was the three corn insects with the lowest mean ratings. Components 8, 9, and 10 were two weeds each with low mean ratings. Component 8 was the same as component 6 for the seven-eigenvalue analysis, which was two annual weeds, fall panicum and crabgrass. Component 9 was two annual weeds, shattercane with the second lowest mean rating and cocklebur with the third highest mean rating. Cocklebur did load on both components 2 and 9 with weights of 46 and 60 , respectively, similar to the grasshoppers as soybean insects. Component 10 was two perennial weeds, common milkweed and hemp dogbane. Component 11 became the component of grasshoppers since grasshoppers as corn insects loaded on this component and grasshoppers as soybean insects had a loading slightly over the cut-off point of 47 on component 4 and a much higher loading of 62 on component 11. The last two components, 12 and 13, each was the weed with the lowest mean ratings in their weed categories, an annual weed (hedge bindweed) and a perennial weed (prickly lettuce), respectively. These two weeds loaded on component 5 together with chinchbugs in the seven-eigenvalue case.

Though the summarization of the variables was diluted using 13 components, the loadings of the rotated components brought out special qualities of the data. The pests were grouped in the six pest categories, where weeds and corn insects were partitioned further according to the magnitude of their mean ratings. The perennial weeds were divided into high (Canada thistle and quackgrass), medium (common milkweed and hemp dogbane), and low (hedge bindweed) mean rating groups. The annual weeds were divided into a high mean rating group of five weeds 
(foxtail, velvetleaf, pigweed, lambsquarter, ragweed, and smartweed) and several lower mean rating groups of one or two weeds (fall panicum and crabgrass; cocklebur and shattercane; prickly lettuce). Similarly, all corn insects except grasshoppers were divided into a group of five high mean ratings (rootworm, corn borer, cutworm, stalk borer, and wireworm) and a group of three low mean ratings (aphid, spider mite, and chinch bug). Grasshoppers as corn insects and soybean insects loaded together on one component, while spider mites, which also occurred as both corn insects and soybean insects, loaded with comparable insects (soybean insects and corn insects with low mean rating, respectively).

The seven and thirteen eigenvalue analyses point to pest category means by themselves or even a further division into sub-category means of pests (in the case of perennial weeds, annual weeds, and corn insects) with high pest mean ratings and low pest mean ratings as adequate summary variables.

\section{SHEIRER-RAY-HARE EXTENSION OF KRUSKAL-WALLIS TEST USING SAS}

This non-parametric test is an extended version of a one-way non-parametric analysis (Sheirer et al, 1976). The SAS ${ }^{\text {TM }}$ System was used for the analyses. Using an example data set (Sokal and Rohlf, 1995) to illustrate the test (see appendix), the data is first ranked using PROC RANK, then PROC GLM is used on the ranks. The test statistics are the sums of squares (SS) for main effects (or interaction) divided by the total mean square. These SS ratios are approximately $\chi^{2}$-distributed with degrees of freedom associated with the SS for the effect. Output data from PROC GLM are used to obtain the SS to create the $\chi^{2}$-statistics. To compare significant effects with more than two levels, the least squares means (lsmeans) from the GLM procedure are used to separate factor levels similar to mean separation in the Kruskal-Wallis test. Interactions were pooled with error at the $25 \%$ level following Bozivich et al. (1956).

\section{PEST CATEGORY MEAN RATING}

The principal component analysis indicated means of pest categories (or sub-categories based on magnitude of mean ratings) as summary variables. To fully use all pests rated, pest category mean ratings were created from all pests in each region excluding wheat pests. Four perennial weeds, six annual weeds, one corn insect, one corn disease, and one soybean insect were included on the survey in the eastern region but not on the version in the western region. One perennial weed, ten annual weeds, and one corn disease were included on the survey in the western region but not on the version in the eastern region. Of all the pests appearing on the two versions of the survey (excluding wheat pests) almost all crop insects and diseases were present on both versions, while there were as many weeds excluded as included on both versions. Thus in the present analysis surveyed ratings of insects and diseases are better utilized than surveyed ratings of weeds.

\section{EFFECTS OF REGION, SOIL TYPE AND TILLAGE}

Individual pest infestation results

Each of the categorical model, general linear model and non-parametric factorial analyses produced similar results for the individual pest ratings, though the data set is not normal and the number of responses in two region-tillage-soil type combinations was low, nine and seventeen respectively (Fig. 2). Only results from the categorical analysis or the non-parametric substitute analysis will be discussed below (Table 2).

Region and/or tillage were very highly significant effects (less than 0.001 ) in all but two pest infestation ratings (mustard and aphid). The aphid rating had a significant soil type effect and the mustard rating a significant tillage effect both at the 0.05 level. The tillage effect was significant 
at 0.001 in 26 pest ratings. In all pests the mean rating was greater in no-till than conventional till whether tillage was significant or not. The region effect was significant at 0.001 in 28 pest ratings and at 0.01 in two more ratings. Mean ratings were greater in the east part of the Midwest than the west part in 25 of these 30 pests. Four of the five pests for which ratings were greater in the western region had the lowest or second lowest mean rating in their pest category. These were hedge bindweed, shattercane, chinch bug, and seedling blight in soybeans. The fifth pest was grasshoppers in corn.

Soil type and factor interactions were less significant effects. Soil type was significant at the 0.001 level in eleven of the 40 pests and at the 0.01 level in eight more pests. When differences in soil type were significant at the 0.01 level, mean ratings in loam were greater than in sand or clay, or mean ratings were greater in clay than in sand. Only two interactions were significant at the 0.001 level and only 15 more of the 160 possible interactions were significant at the 0.01 level. The p-values should not be used "as is" since 40 analyses are carried out; on the other hand, variables were correlated so p-values should not be multiplied by a factor of 40 either.

\section{Pest category means results}

Except for perennial weed and corn insect mean ratings, the chi-square value of region effect was larger than the chi-square value of tillage (Table 3). All pest category mean ratings had a very highly significant $(0.0001)$ tillage effect. Interactions were significant in weed and soybean insect mean ratings.

The mean weed ratings kept all interactions in the final model. While mean ratings differed more due to tillage than region in perennial weeds, it was the opposite in annual weeds. Soil type and interactions were not significant in the annual weed mean rating. The perennial mean rating had highly significant (0.01) soil type and region-soil type interaction effects. Soil type differences in the perennial weed mean rating were in loam and sand but changed with region.

Tillage was significant at 0.0001 , while soil type was significant at 0.001 in the corn insect rating. Differences in severity of corn insect infestation depend on tillage and, to a lesser degree, soil type and region. The soil type effect was due to rating differences between loam and each of clay and sand. The most significant effect in soybean insect mean rating was region followed by tillage (0.0001) while soil type and soil type-tillage interaction effects were significant at 0.001 . Ratings were different between sand and either clay or loam but changed some with tillage.

The corn disease mean rating had very highly significant $(0.0001)$ region and tillage effects, a significant soil type effect due to a difference between loam and sand and no significant interactions. The soybean disease mean rating also had very highly significant $(0.0001)$ region and tillage effects and no significant interactions. The soil type effect was significant at 0.001 due mostly to a difference between loam and sand (significant at 0.0001) and to a lesser degree between clay and sand (significant at 0.05 ).

Perennial weed and corn insect ratings differed most in tillage and much less in region, while annual weed and soybean pest ratings differed more in region than in tillage. Corn disease ratings differed in both region and tillage at the same scale. There were differences in soil types mainly due to loam and sand only in perennial weed, crop insect and soybean disease ratings.

\section{Three eigenvalues results}

The rotated components based on the first three eigenvalues were soybean pests, weeds, and corn pests. Non-parametric analysis was used for three comparable sets of variables: rotated components, the sum of corresponding component selected variables, and the pest category means (Table 4). Results from the analysis involving the sum of the loading variables of soybean pests, corn pests or weeds were more different from results using the rotated components themselves than from results using the pest category mean ratings (obtained from all pests on either version of the survey). The greatest difference in summary variables for soybean pests was the interactions with tillage and soil type and the greatest difference in summary variables for corn pests was that 
soil type changed from not significant to significant at the 0.0001 level. This is not surprising since almost all pests in these categories were included in both versions of the survey. In both soybean pests and corn pests the main effects were the most significant. For soybean pests region was four times as important as tillage which was twice as important as soil type. Interactions were at most as important as soil type. Differences in soil type for soybean pests were due to sand. For corn pests only the main effects stayed in the model. Here region and tillage were equally important while soil type was a sixth of the other two effects. Differences in soil type for corn pests were due to loam.

The analyses of the rotated weed component and corresponding component selected variables were similar, but region and tillage effects switched in importance when using the two weed mean ratings. Incorporating all weeds through the mean ratings lowered the region effect and increased the tillage effect while there was no change in soil type and interaction effects.

The soybean component and the weed component each had twice as large an R-square $(0.117$ and 0.111$)$ as the corn component $(0.050)$ in the results of the GLM procedure (analysis not shown) used on the ranks suggesting that severity of soybean pest and weed infestations are more dependent on region, tillage, and soil type than are corn pest infestations.

\section{Thirteen eigenvalues results}

The sum of pest ratings included in each of the rotated components from the thirteen eigenvalue analysis had region effects that were significant at the 0.0001 level except four components: corn insects with low mean ratings, annual weeds with mixed mean ratings, grasshoppers, and prickly lettuce (the annual weed with lowest mean rating) (Table 5). Region was significant in prickly lettuce at the 0.01 level but not significant in the three other components. Soil type was significant at the 0.001 level only in three components: corn insects with high mean ratings, annual weeds with mixed mean ratings, and perennial weeds with medium mean ratings. In six other components (annual weeds with high mean ratings, soybean diseases, soybean insects, corn diseases, corn insects with low mean ratings, and grasshoppers) soil type was significant at the 0.01 level and in three more components (annual weeds with low mean ratings, annual weeds with lowest mean ratings, and perennial weeds with lowest mean ratings) at the 0.05 level. Only in perennial weeds with high mean ratings was soil type not significant. Tillage was not significant in perennial weeds with high mean ratings either, but was significant at the 0.0001 level in all other components. Interactions were significant at most at the 0.05 level and some or all interactions could be discarded in most analyses.

\section{SUMMARY}

It is important to keep in mind that the survey responses are farmers' perceptions of severity of pest infestation in their fields. Analysis results therefor report on perceptions and not actual levels of severity of pest infestation.

Natural breakpoints using the scree-plot, the sizes of the eigenvalues, and the variance contributions of the components resulted in three sets of components based on three, seven, and thirteen eigenvalues, respectively. Each of the sets of components clarified aspects of the data set. The set of three components was the most summarizing and pointed toward using pest categories together in groups of two, weeds together, soybean pests together and corn pests together. The set of seven components kept the weed and soybean insect components and divided the corn pest component into an corn insect component and a corn disease component, while the last three components had a more meaningful interpretation when compared to the set of components for thirteen eigenvalues.

Summary variables based on the components of the 13 eigenvalues analysis were as follows (rank of eigenvalue is in parenthesis): 5 corn insects with high mean ratings (1), 3 corn insects with low mean ratings (7), 5 annual weeds with high mean ratings (2), 2 annual weeds with low mean ratings (8), annual weeds with mixed mean ratings (9), annual weed with lowest 
mean ratings (12), soybean diseases (3), soybean insects (4), corn diseases (5), perennial weeds with high mean ratings (6), perennial weeds with low mean ratings (10) and perennial weed with lowest mean ratings (13). Each the first six components represents a pest category. The divided pest categories then appear as components again in the same order as in the first six components.

In most of the individual pest rating analyses region and tillage were the most important factors, while soil type and interactions were less important factors. The mean ratings in no-till were greater than the mean ratings in conventional till in all individual pests, and the mean ratings in the eastern region was greater than the mean ratings in the western region in 25 of 30 pests. The five pests that had greater ratings in the western region were grasshopper as corn insects and the four pests with the lowest or second lowest mean rating in each of the perennial and annual weeds, corn insects and soybean diseases. Most significant differences due to soil type were between loam and sand, with fewer between clay and sand, and loam and sand. The mean ratings were highest in loam, followed by mean ratings in clay and then mean ratings in sand.

In the three-eigenvalue case the summary variables had the same relationships in tillage, region and soil type, whether the variables were the rotated components, the sum of the variables themselves, or the pest category mean ratings. When considering thirteen eigenvalues the sum of loading variables of a component were substituted for the rotated component itself in the factorial analysis of the principal components. The analysis results for the sum of loading variables had almost exclusively significant main effects. Tillage was significant at 0.0001 and soil type was significant at 0.05 in all components except for perennial weeds with high ratings, where the effects were not significant and only region had an impact. Hence only the component of Canada thistle and quackgrass was not affected by tillage. Soil type effects were mostly due to differences between loam and sand. Region was significant at 0.0001 and the largest effect in eight of the thirteen components, but was not significant in corn insects with low mean ratings, annual weeds with mixed mean ratings, and grasshoppers. Region was a smaller effect than tillage in soybean insects and the annual weed with the lowest mean rating (prickly lettuce). Since region is both a factor of more or less precipitation and of different corn/sorghum ratios, differences in region for corn pests (includes both corn and sorghum pests) may be due to a combination of the precipitation factor and the change in ratio of the acreage of the two crops, while differences in region for soybean pests and weeds may be seen more as a precipitation factor.

ACKNOWLEDGMENTS. I thank David R. Pike for the use of the data from the 1992 Midwest farmer survey. I also thank the reviewer for great comments and suggestions.

\section{REFERENCES}

Bozivich, H,. T.A. Bancroft, and H.O. Hartley. 1956. Ann. Math. Statist. 27:1017

Dexter, A.G., J.D. Nalewaja, D.D. Rasmussen, and J. Buchli. 1981. Survey of Wild Oats and Other Weeds in North Dakota 1978 and 1979. North Dakota Research Report. Number 79.

Hatcher, L. and E.J. Stepanski. 1994. A step-by-step approach to using the SAS ${ }^{\mathrm{TM}}$ System for Univariate and Multivariate Statistics. Chapter 14.

Loux, M.M. and M.A. Berry. 1991. Use of a Grower Survey for Estimating Weed Problems. Weed Technology. 5:460-466.

Pike, D.R., S. Kamble, and H.W. Kirby. 1997. Distribution of Severity of Pests in the Midwest.

Sheirer, C.J., W.S. Ray, and N. Hare. 1976. The analysis of ranked data derived from completely randomized factorial designs. Biometrics 32:429-434.

Sokal, R.R. and F.J. Rohlf. 1995. Biometry. W.H. Freeman and Co. New York.

Stoller, E.W., L.M. Wax, and D.M. Alm. 1993. Survey Results on Environmental Issues and Weed Science Research Priorities within the Corn Belt. Weed Technology. 7:763-770. 


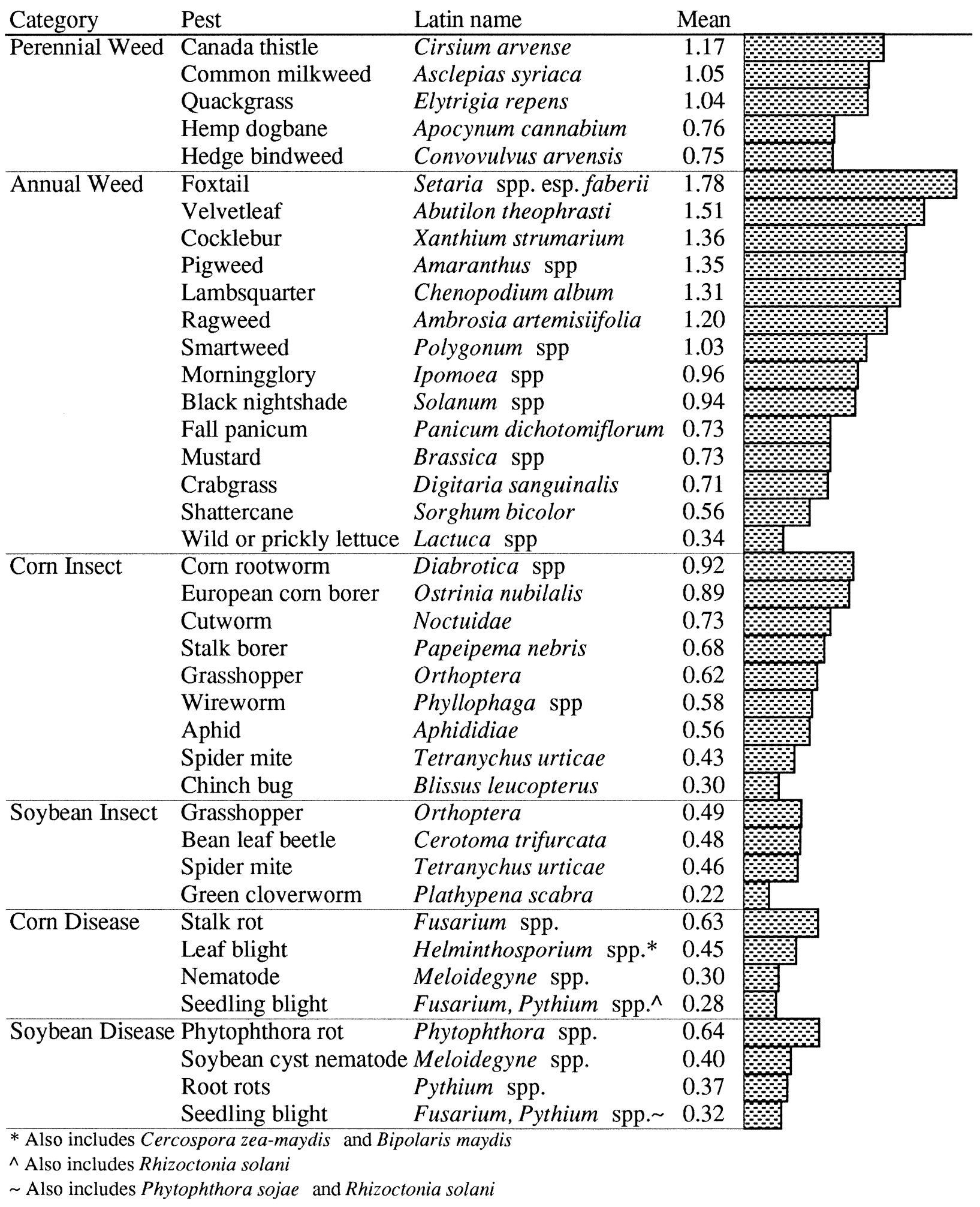

Figure 1. Identification of individual pests and their mean ratings. 


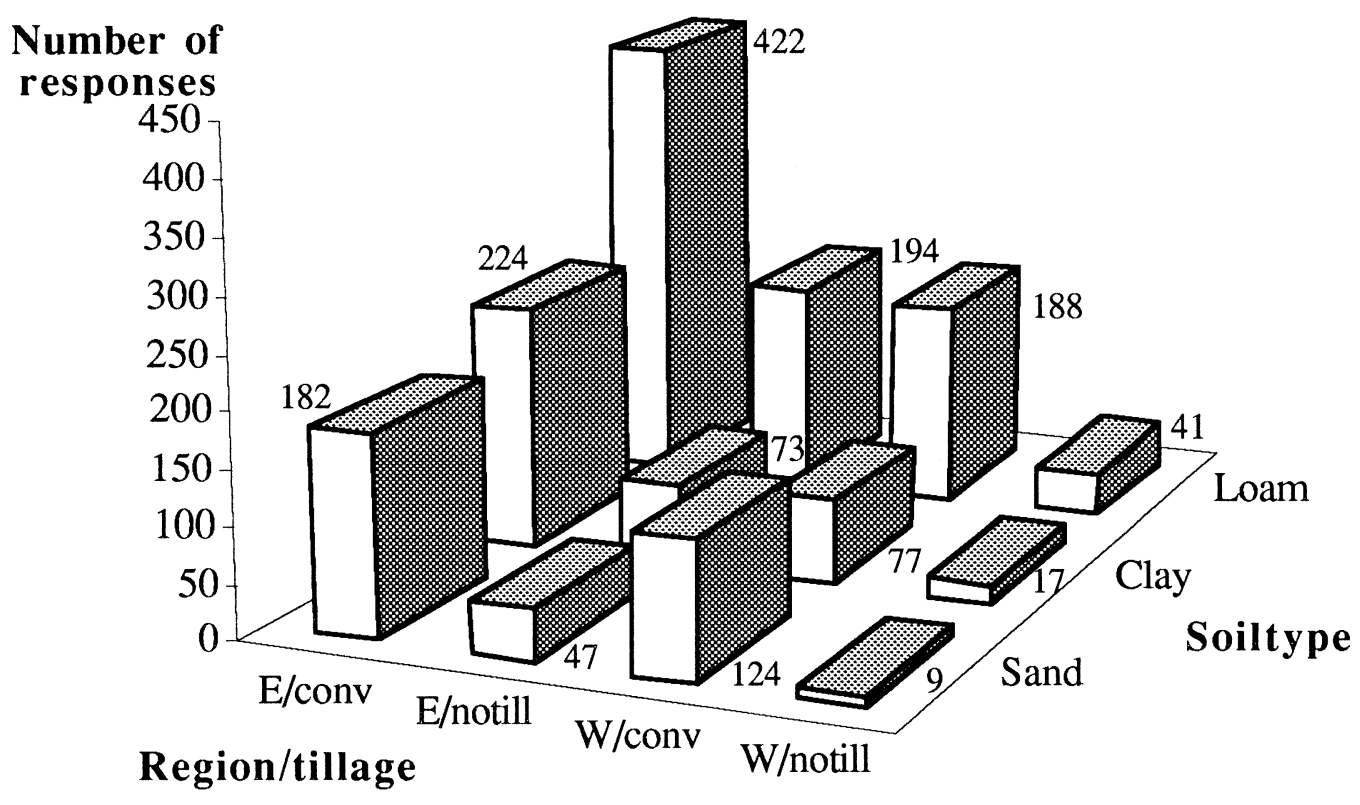

Figure 2. Number of responses in each of the twelve region-soil type and tillage combinations.

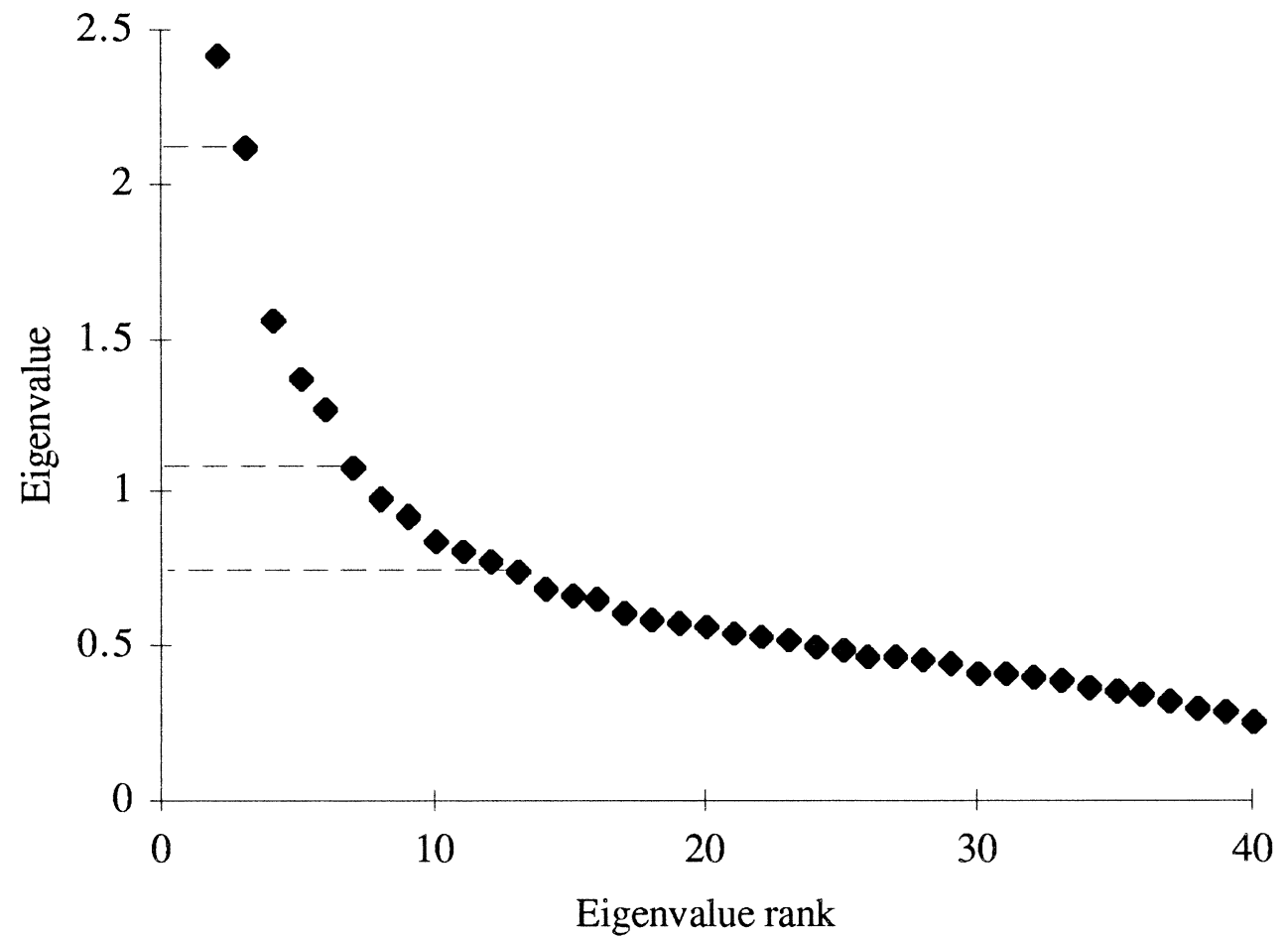

Figure 3. Scree plot. The first eigenvalue of 12.37 is excluded. Vertical lines mark the third, seventh and thirteenth eigenvalue. 
Table 1. Loadings on rotated components in principal component analysis using three, seven, and thirteen eigenvalues, respectively.

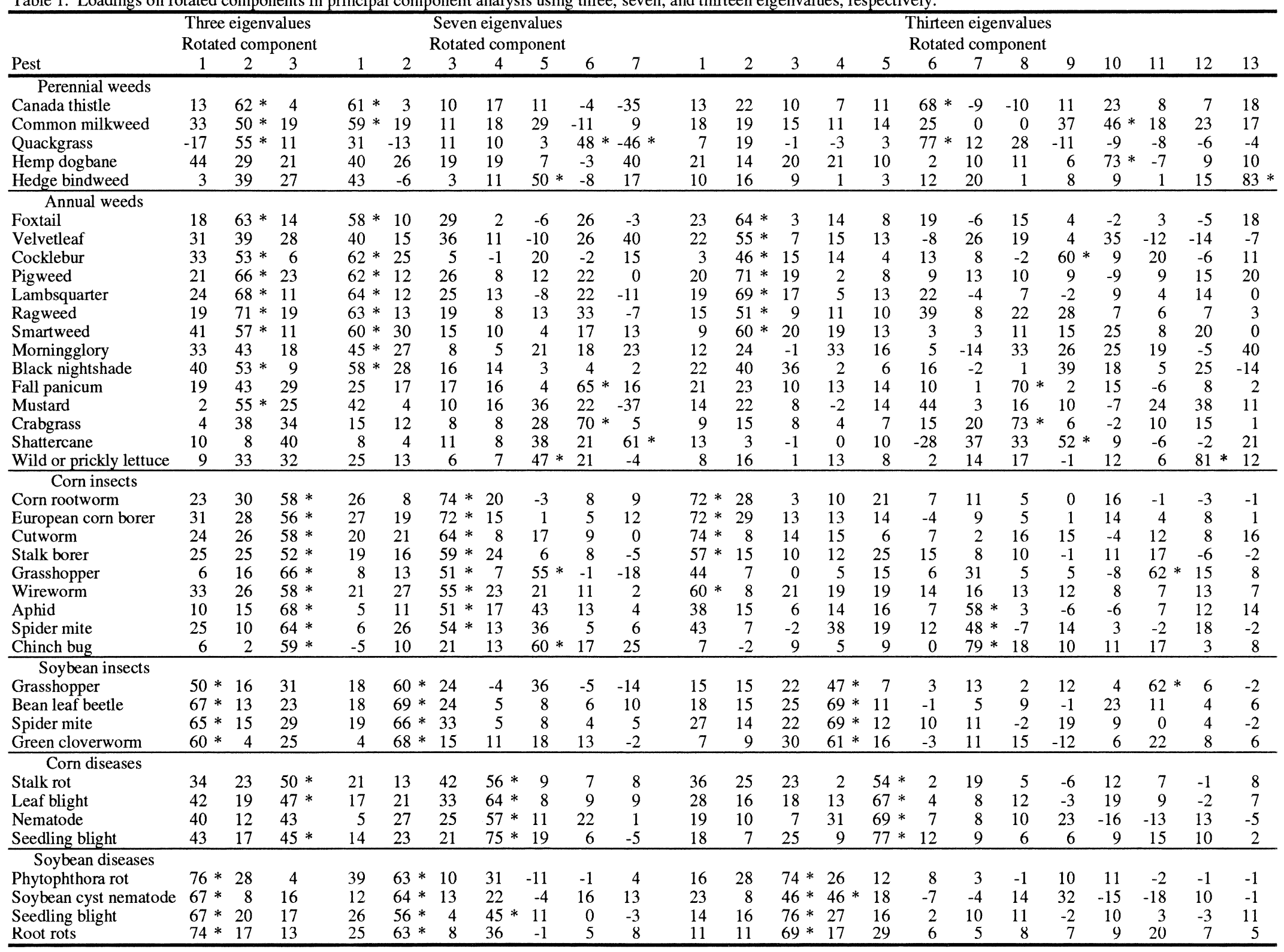

New Prairie Press

https://newprairiepress.org/agstatconference/1997/proceedings/7 
Table 2. Individual pest infestation ratings categorical analysis ${ }^{\circ}$

\begin{tabular}{|c|c|c|c|c|c|c|c|c|c|c|c|c|}
\hline Category 1 & Pest & Region & & Soil type & $\mathrm{R} * \mathrm{~S}^{\circ 0}$ & Tillage & $\mathrm{R} * \mathrm{~T}$ & $\mathrm{~S} * \mathrm{~T}$ & $\mathrm{R} * \mathrm{~S} * \mathrm{~T}$ & $\mathrm{Cl}$ & $\mathrm{CS}$ & $\mathrm{LS}$ \\
\hline \multirow{5}{*}{$\begin{array}{r}\text { Perennial } \\
\text { weeds }\end{array}$} & Canada thistle & 12.9 & $* * *$ & $8.7 *$ & $10.6 * *$ & $7.4 * *$ & 3.4 & 2.2 & $8.6 *$ & * & & * \\
\hline & Com. milkweed & 5.1 & $*$ & $13.0 * *$ & 5.0 & $20.3 * * * *$ & 3.2 & 4.5 & - & & $* *$ & $* * *$ \\
\hline & Quackgrass & 65.1 & $* * * *$ & $7.8 *$ & $6.2 *$ & 0.0 & $4.3 *$ & - & - & & & $* *$ \\
\hline & Hemp dogbane & 49.9 & $* * * *$ & $23.3 * * * *$ & - & $33.2 * * * *$ & 3.4 & $6.7 *$ & - & $*$ & $* *$ & $* * *$ \\
\hline & Hedge bindweed & 48.1 & $* * * *$ & 3.9 & 3.2 & $29.2 * * * *$ & $7.0 * *$ & 4.3 & - & & & \\
\hline \multirow{14}{*}{$\begin{array}{l}\text { Annual } \\
\text { weeds }\end{array}$} & Foxtail & 27.1 & $* * * *$ & $13.1 * *$ & - & $32.5 * * * *$ & $15.5 * * *$ & - & - & & $* *$ & $* * *$ \\
\hline & Velvetleaf & 97.0 & $* * * *$ & $19.2 * * * *$ & 5.1 & $3.8 *$ & - & - & - & & $* * *$ & $* * *$ \\
\hline & Cocklebur & 0.2 & & $10.2 * *$ & - & $22.3 * * * *$ & $5.6 *$ & - & - & & * & ** \\
\hline & Pigweed & 3.6 & & $7.7 *$ & - & $14.6 * * * *$ & 3.5 & - & - & & & $* *$ \\
\hline & Lambsquarter & 70.6 & $* * * *$ & $10.4 * *$ & 4.6 & $11.2 * * *$ & 0.3 & $6.6 *$ & $8.0 *$ & $* *$ & & $*$ \\
\hline & Ragweed & 142.0 & $* * * *$ & 4.5 & 3.5 & $21.9 * * * *$ & - & - & - & & & \\
\hline & Smartweed & 77.6 & $* * * *$ & $23.1 * * * *$ & - & $31.2 * * * *$ & - & - & - & & $* *$ & $* * *$ \\
\hline & Morningglory & 53.5 & $* * * *$ & $8.7 *$ & - & $13.7 * * *$ & 3.4 & - & - & & $* *$ & $* *$ \\
\hline & Black nightshade & 36.5 & $* * * *$ & 4.9 & 4.3 & $19.7 * * * *$ & - & - & - & $*$ & & \\
\hline & Fall panicum & 132.4 & $* * * *$ & 3.3 & $11.8 * *$ & $29.6 * * * *$ & - & - & - & & * & \\
\hline & Mustard & 0.2 & & 5.3 & - & $4.9 *$ & 2.3 & 5.1 & - & & $*$ & \\
\hline & Crabgrass & 14.1 & $* * *$ & $7.8 *$ & $6.1 *$ & $14.6 * * * *$ & - & - & - & * & & * \\
\hline & rcane & 31.1 & $* * * *$ & 4.8 & 3.9 & $8.3 * *$ & - & - & - & & $*$ & \\
\hline & Prickly lettuce & 3.7 & & $6.8 *$ & 2.3 & $11.6 * * *$ & 0.0 & $7.5 * *$ & $6.0 *$ & & & $*$ \\
\hline \multirow{9}{*}{$\begin{array}{l}\text { Corn } \\
\text { insects }\end{array}$} & Corn rootworm & 64.6 & $* * * *$ & $18.1 * * *$ & - & 3.0 & - & - & - & $* * *$ & & $* * *$ \\
\hline & Eur. corn borer & 3.0 & & $17.6 * * * *$ & $11.1 * *$ & $13.2 * * *$ & 3.3 & 1.4 & $9.3 * *$ & $* * * *$ & $*$ & \\
\hline & Cutworm & 5.1 & & 2.7 & - & $32.2 * * * *$ & - & - & - & & & \\
\hline & Stalk borer & 67.7 & $* * * *$ & $11.6 * *$ & - & 0.3 & $4.9 *$ & - & - & & & $* * *$ \\
\hline & Grasshopper & 7.9 & $* *$ & 0.3 & - & $17.9 * * * *$ & 2.6 & - & - & & & \\
\hline & Wireworm & 13.0 & $* * *$ & $16.0 * * *$ & 5.7 & $17.5 * * * *$ & 0.1 & 5.7 & $6.1 *$ & $* * *$ & & $*$ \\
\hline & Aphid & 1.3 & & $9.1 *$ & 5.1 & 2.1 & - & - & - & & & $* *$ \\
\hline & Spider mite & 0.0 & & 5.8 & 5.0 & $16.0 * * * *$ & - & - & - & $*$ & & \\
\hline & Chinch bug & 22.0 & $* * * *$ & $26.8 * * * *$ & $8.1 *$ & $8.5 * *$ & - & - & - & & $* * * *$ & $* *$ \\
\hline \multirow{4}{*}{$\begin{array}{l}\text { Soybean } \\
\text { insects }\end{array}$} & Grasshopper & 5.5 & & $25.0 * * * *$ & - & $12.8 * * *$ & - & $15.3 * * *$ & - & & $* * * *$ & $* * *$ \\
\hline & Bean leaf beetle & 72.0 & $* * * *$ & $17.5 * * *$ & - & $31.1 * * * *$ & - & $12.4 * *$ & - & & $* * *$ & $* * *$ \\
\hline & Spider mite & 84.2 & $* * * *$ & $6.8 *$ & - & $17.5 * * * *$ & - & $9.3 * *$ & - & & & $* *$ \\
\hline & Cloverworm & 39.6 & $* * * *$ & $9.2 * *$ & - & 1.5 & $5.8 *$ & $11.9 * *$ & - & & & $* *$ \\
\hline \multirow{4}{*}{$\begin{array}{l}\text { Corn } \\
\text { diseases }\end{array}$} & Stalk rot & 9.5 & $* *$ & $18.0 * * * *$ & - & $6.7 * *$ & - & - & - & & $*$ & $* * *$ \\
\hline & Leaf blight & 49.3 & $* * * *$ & $8.6 *$ & - & $12.8 * * *$ & - & $6.2 *$ & - & & $*$ & $* *$ \\
\hline & Nematode & 18.2 & $* * * *$ & 1.0 & 4.1 & $4.0 *$ & - & - & - & & & \\
\hline & Seedling blight & 17.3 & $* * * *$ & 5.2 & - & $12.0 * * *$ & - & - & - & & & $*$ \\
\hline \multirow{4}{*}{$\begin{array}{l}\text { Soybean } \\
\text { diseases }\end{array}$} & Phytophthora rot & 77.4 & $* * * *$ & $8.7 *$ & - & $28.5 * * * *$ & - & $7.6 *$ & - & & $* *$ & $* *$ \\
\hline & Cyst nematode & 116.8 & $* * * *$ & $9.3 * *$ & - & 2.7 & - & - & - & $* *$ & & \\
\hline & Root rots & 53.1 & $* * * *$ & $17.0 * * *$ & - & $29.7 * * * *$ & - & - & - & & $*$ & $* * *$ \\
\hline & Seedling blight & 14.3 & $* * *$ & $11.2 * *$ & $6.1 *$ & $9.6 * *$ & 1.5 & 2.7 & $10.6 * *$ & & * & $* * *$ \\
\hline \multicolumn{13}{|c|}{$\begin{array}{l}\text { For the } 40 \text { individual ratings analyses p-values should be multiplied by a factor between one and } 40 \text {. Effects in the table } \\
\text { that are significant only at the } 0.05 \text { level should be disregarded. Highly significant effects should be considered at most } \\
\text { at the } 0.1 \text { level. Very highly significant }(\mathrm{p}=0.001) \text { effects are now } 4 \%, 2 \% \text { or } 1 \% \text {, depending on the size of the factor } \\
\text { chosen. }\end{array}$} \\
\hline
\end{tabular}


Table 3. Pest category mean ratings: Non-parametric factorial analysis ${ }^{\circ}$

\begin{tabular}{llcrrrrc}
\hline Category & Region & Soil & $\mathrm{R} * \mathrm{~S}$ & Tillage & $\mathrm{R}^{* T}$ & $\mathrm{~S} * \mathrm{~T}$ & $\mathrm{R}^{*} \mathrm{~S} * \mathrm{~T}$ \\
\hline Perennial weed & $11.5 * * *$ & $10.4 * *$ & $10.0 * *$ & $30.5 * * * *$ & 0.4 & 4.5 & 4.3 \\
Annual weed & $40.1 * * * *$ & 3.8 & 2.5 & $28.2 * * * *$ & 0.0 & 3.1 & $6.0 *$ \\
Corn insect & $14.0 * * *$ & $14.8 * * *$ & - & $26.0 * * * *$ & - & - & - \\
Soybean insect & $56.7 * * * *$ & $14.8 * * *$ & - & $35.5 * * * *$ & - & $10.5 * *$ & - \\
Corn disease & $16.9 * * * *$ & $8.8 *$ & - & $15.4 * * * *$ & - & - & - \\
Soybean disease & $78.8 * * * *$ & $9.7 * * *$ & - & $32.6 * * * *$ & - & 4.3 & - \\
Overall mean & $58.6 * * * *$ & $12.1 * *$ & - & $64.6 * * * *$ & - & - & - \\
\hline
\end{tabular}

- Because of the number of analyses, $p$-values should be multiplied by a factor between one and six.

Table 4. Non-parametric analysis results of modeling three rotated components, corresponding loading variables and corresponding pest category means on factorial effects of region, soil type, tillage.

\begin{tabular}{|c|c|c|c|c|c|c|c|c|}
\hline & & $\mathrm{Ro}$ & tated C & mponents & Vari & ables & Category & Means \\
\hline & SOURCE & $\mathrm{DF}$ & $\mathrm{H}$ & $\mathrm{P}>\mathrm{H}$ & $\mathrm{H}$ & $\mathrm{P}>\mathrm{H}$ & $\underline{\mathrm{H}}$ & $\mathrm{P}>\mathrm{H}$ \\
\hline Soybean pests & REGION & 1 & 54.02 & 0.0000 & 52.54 & 0.0000 & 50.19 & 0.0000 \\
\hline & SOIL TYPE & 2 & 7.87 & 0.0195 & 12.95 & 0.0015 & 12.98 & 0.0015 \\
\hline & REGION*SOIL & 2 & 6.35 & 0.0418 & 1.56 & 0.4594 & 1.62 & 0.4452 \\
\hline & TILLAGE & 1 & 10.81 & 0.0010 & 12.97 & 0.0003 & 13.60 & 0.0002 \\
\hline & REGION*TILL & 1 & 6.41 & 0.0114 & 3.45 & 0.0633 & 3.72 & 0.0538 \\
\hline & SOIL*TILL & 2 & 9.26 & 0.0097 & 4.07 & 0.1305 & 4.09 & 0.1297 \\
\hline & REG*SOIL*TILL & 2 & & & 4.17 & 0.1244 & 4.52 & 0.1042 \\
\hline Weeds & REGION & 1 & 23.33 & 0.0000 & 36.77 & 0.0000 & 22.30 & 0.0000 \\
\hline & SOIL TYPE & 2 & 3.56 & 0.1683 & 8.02 & 0.0181 & 8.49 & 0.0143 \\
\hline & REGION*SOIL & 2 & 4.37 & 0.1123 & 2.79 & 0.2479 & 6.05 & 0.0486 \\
\hline & TILLAGE & 1 & 15.35 & 0.0001 & 22.60 & 0.0000 & 35.33 & 0.0000 \\
\hline & REGION*TILL & 1 & 3.47 & 0.0626 & 1.23 & 0.2682 & 0.10 & 0.7534 \\
\hline & SOIL*TILL & 2 & 8.00 & 0.0183 & 4.51 & 0.1049 & 4.28 & 0.1175 \\
\hline & REG*SOIL*TILL & 2 & 6.70 & 0.0352 & 5.16 & 0.0756 & 5.76 & 0.0562 \\
\hline Corn pests & REGION & 1 & 13.17 & 0.0003 & 25.86 & 0.0000 & 21.90 & 0.0000 \\
\hline & SOIL TYPE & 2 & 2.75 & 0.2534 & 18.12 & 0.0001 & 15.00 & 0.0006 \\
\hline & TILLAGE & 1 & 9.43 & 0.0021 & 25.66 & 0.0000 & 24.57 & 0.0000 \\
\hline Comparisons o & soil types & & $>|\mathrm{T}| \mathrm{HC}$ & LSMEAN & (i) $=\mathrm{LSM}$ & $\operatorname{EAN}(j)$ & & \\
\hline & Soybean pes & & & Weec & & & Corn pe & sts \\
\hline & 2 & 3 & & 2 & 3 & 1 & 2 & 3 \\
\hline$\overline{\text { CLAY }}$ & 0.21630 & .0145 & & 0.3411 & 0.0447 & & 0.0167 & 0.6440 \\
\hline LOAM & 0.2163 & .0001 & 0.3 & & 0.0022 & 0.016 & & 0.0118 \\
\hline SAND & $\begin{array}{ll}0.0145 & 0.0001 \\
\end{array}$ & & 0.0 & $47 \quad 0.0022$ & & 0.644 & $0 \quad 0.0118$ & \\
\hline
\end{tabular}


Table 5. Non-parametric factorial analyses of totals of pest ratings loading on thirteen eigenvalues in a principal component analysis.

\begin{tabular}{|c|c|c|c|c|c|c|c|}
\hline \multirow[b]{2}{*}{ NAME } & \multirow[b]{2}{*}{ SOURCE } & \multirow[b]{2}{*}{ DF } & \multirow[b]{2}{*}{$\mathrm{H}$} & \multirow[b]{2}{*}{ P CHI } & \multicolumn{3}{|c|}{ Differences in soiltypes } \\
\hline & & & & & C-L & C-S & L-S \\
\hline Corn insects/high mean ratings & Region & $T$ & 59.88 & 0.0000 & & & \\
\hline w/o grasshoppers & Soil type & 2 & 18.15 & 0.0001 & 0.0004 & 0.8453 & 0.0003 \\
\hline & Tillage & 1 & 21.55 & 0.0000 & & & \\
\hline \multirow[t]{3}{*}{ Annual weeds/high mean ratings } & Region & 1 & 52.58 & 0.0000 & & & \\
\hline & Soil type & 2 & 13.41 & 0.0012 & 0.5290 & 0.0047 & 0.0001 \\
\hline & Tillage & 1 & 35.32 & 0.0000 & & & \\
\hline \multirow[t]{3}{*}{3 Soybean diseases w/o nematodes } & Region & 1 & 65.49 & 0.0000 & & & \\
\hline & Soil type & 2 & 21.16 & 0.0000 & 0.0991 & 0.0051 & 0.0001 \\
\hline & Tillage & 1 & 41.38 & 0.0000 & & & \\
\hline \multirow{4}{*}{4 Soybean insects w/o grasshoppers } & Region & 1 & 9.88 & 0.0017 & & & \\
\hline & Soil type & 2 & 9.69 & 0.0079 & 0.0457 & 0.2909 & 0.0016 \\
\hline & Tillage & 1 & 22.38 & 0.0000 & & & \\
\hline & Region*Tillage & 1 & 2.30 & 0.1295 & & & \\
\hline \multirow{3}{*}{$\begin{array}{ll}5 & \text { Corn diseases }\end{array}$} & Region & 1 & 36.60 & 0.0000 & & & \\
\hline & Soil type & 2 & 11.48 & 0.0032 & 0.0799 & 0.1434 & 0.0007 \\
\hline & Tillage & 1 & 15.01 & 0.0001 & & & \\
\hline \multirow[t]{7}{*}{6 Perennial weeds/high mean ratings } & Region & 1 & 46.68 & 0.0000 & & & \\
\hline & Soil type & 2 & 2.52 & 0.2833 & 0.1706 & 0.9120 & 0.2050 \\
\hline & Region*Soil type & 2 & 8.43 & 0.0148 & & & \\
\hline & Tillage & 1 & 2.22 & 0.1359 & & & \\
\hline & Region*Tillage & 1 & 3.85 & 0.0970 & & & \\
\hline & Soil type*Tillage & 2 & 3.61 & 0.1648 & & & \\
\hline & Region*Soil*Till & 2 & 6.36 & 0.0417 & & & \\
\hline \multirow[t]{3}{*}{$7 \quad$ Corn insects/low mean ratings } & Region & 1 & 1.91 & 0.1669 & & & \\
\hline & Soil type & 2 & 11.12 & 0.0038 & 0.1280 & 0.1099 & 0.0009 \\
\hline & Tillage & 1 & 16.25 & 0.0000 & & & \\
\hline \multirow[t]{3}{*}{$8 \quad$ Annual weeds/low mean ratings } & Region & 1 & 99.10 & 0.0000 & & & \\
\hline & Soil type & 2 & 7.83 & 0.0200 & 0.0921 & 0.3131 & 0.0052 \\
\hline & Tillage & 1 & 25.04 & 0.0000 & & & \\
\hline \multirow[t]{4}{*}{9 Annual weeds/mixed mean ratings } & Region & 1 & 3.69 & 0.0546 & & & \\
\hline & Soil type & 2 & 15.75 & 0.0003 & 0.1802 & 0.0001 & 0.0016 \\
\hline & Region*Soil type & 2 & 5.02 & 0.0814 & & & \\
\hline & Tillage & 1 & 19.19 & 0.0000 & & & \\
\hline \multirow{5}{*}{10 Perennial weeds/med. mean ratings } & Region & 1 & 61.80 & 0.0000 & & & \\
\hline & Soil type & 2 & 22.52 & 0.0000 & 0.2974 & 0.0004 & 0.0001 \\
\hline & Region*Soil type & 2 & 3.16 & 0.2057 & & & \\
\hline & Tillage & 1 & 28.37 & 0.0000 & & & \\
\hline & Soil type*Tillage & 2 & 4.37 & 0.1126 & & & \\
\hline \multirow[t]{4}{*}{ Grasshe } & Region & 1 & 0.09 & 0.7671 & & & \\
\hline & Soil type & 2 & 11.07 & 0.0039 & 0.7821 & 0.0029 & 0.0015 \\
\hline & Tillage & 1 & 15.96 & 0.0001 & & & \\
\hline & Soil type*Tillage & 2 & 6.50 & 0.0388 & & & \\
\hline \multirow[t]{4}{*}{$12 \quad$ Annual weed/lowest mean rating } & Region & 1 & 9.98 & 0.0016 & & & \\
\hline & Soil type & 2 & 6.22 & 0.0447 & 0.2801 & 0.1744 & 0.0127 \\
\hline & Tillage & 1 & 25.09 & 0.0000 & & & \\
\hline & Soil type* & 2 & 5.85 & 0.0537 & & & \\
\hline 13 Perennial weed/lowest mean ratings & Region & 1 & 45.17 & 0.0000 & & & \\
\hline & Soil type & 2 & 6.87 & 0.0322 & 0.5158 & 0.0116 & 0.0188 \\
\hline & Region*Soil type & 2 & 4.46 & 0.1073 & & & \\
\hline & Tillage & 1 & 24.17 & 0.0000 & & & \\
\hline & Soil type*Tillage & 2 & 3.96 & 0.1380 & & & \\
\hline
\end{tabular}




\begin{abstract}
APPENDIX: SAS program for a non-parametric factorial analysis, SHEIRER-RAY-HARE extension of the Kruskal-Wallis test. Data from Sokal and Rohlf (1995). A study of differences in food consumption of rats with factors lard (rancid and fresh) and sex.
\end{abstract}

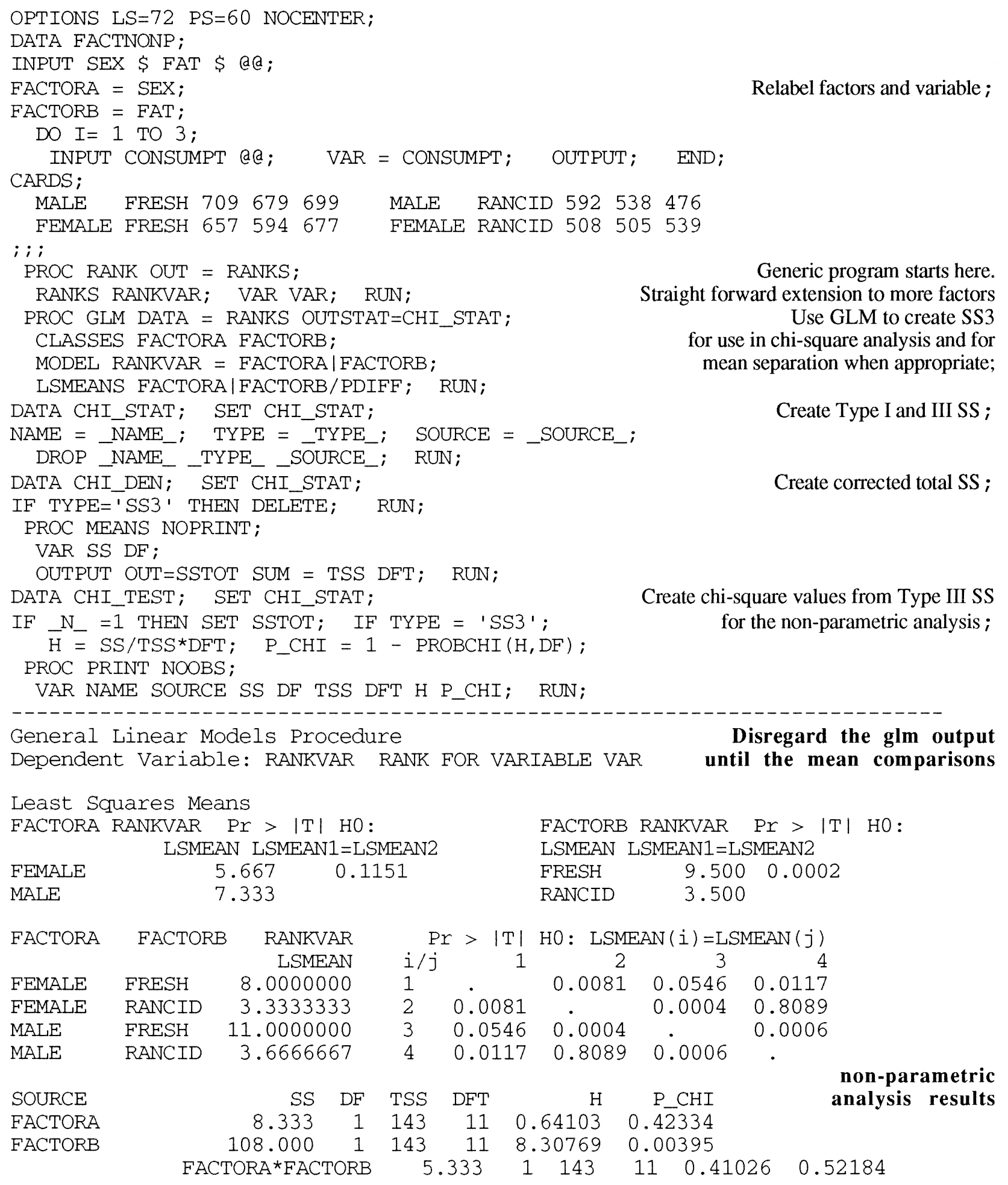

